\title{
Targeting mulitple dyslipidemias with fixed combinations - focus on extended release niacin and simvastatin
}

\author{
Anbu Pandian' \\ Anjali Arora ${ }^{2}$ \\ Laurence S Sperling' \\ Bobby V Khan' \\ 'Emory University School of Medicine \\ and Grady Memorial Hospital Vascular \\ Research Atlanta, Georgia USA; ${ }^{2}$ Sir \\ Ganga Ram Hospital, New Delhi, India
}

\begin{abstract}
Dyslipidemia is a major risk factor in the initiation and progression of cardiovascular diseases such as atherosclerosis. Several pharmacological agents have been developed over the past 50 years which target various lipid components such as low density lipoprotein (LDL) cholesterol, triglyceride, and high density lipoprotein (HDL) cholesterol. Similar to other risk factors such as hypertension and diabetes mellitus, the management of dyslipidemia can be complicated and may require combination therapy for effective treatment. This review discusses the biochemical mechanisms of action and clinical uses for simvastatin (the most widely available and commercially prescribed statin) and niacin, and the combination of these agents in the management and treatment of dyslipidemia.
\end{abstract}

Keywords: dyslipidemia, HDL cholesterol, triglyceride, statin, niacin

\section{Introduction}

'Multiple dyslipidemia' is a collective term for the low HDL-cholesterol, elevated triglycerides (TG), and small, dense LDL-cholesterol that is often found in insulinresistant patients with abdominal obesity, metabolic syndrome, or type 2 diabetes (Krauss et al 2004). Current guidelines for the management of cardiovascular risk focus firmly on the control of individual cardiovascular risk factors, such as dyslipidemia, hypertension, and obesity (NCEP 2002; Grundy et al 2004). For dyslipidemia, these guidelines focus firmly on the control of LDL-cholesterol as the primary objective, with the control of other lipid components viewed as a secondary objective.

The clinical benefits and safety of statin-based therapy, particularly simvastatin, are proven by many well-designed intervention trials (Kastelein et al 2005). Despite the impressive benefits with statins, there remains a significant residual cardiovascular risk for events. The National Cholesterol Education Program (NCEP) Adult Treatment Panel (ATP) III guidelines recognize low HDL (1.03 mmol/L or $40 \mathrm{mg} / \mathrm{dL}$ ) as an independent major risk factor for coronary heart disease and as a potential target for therapeutic intervention.

The presentation of dyslipidemic phenotypes is heterogeneous, and combination therapy with agents (statins) to reduce LDL-cholesterol with agents (eg, niacin and fibrates) that correct low HDL-cholesterol and hypertriglyceridemia provides a rational strategy for addressing cardiovascular risk arising from these multiple sources. Niacin is an effective pharmacological agent available to increase levels of HDL-cholesterol (NCEP 2002), and this compound also induces substantial reductions in TG. Furthermore, niacin therapy shifts the LDL subclass profile towards larger, less atherogenic particles (McGovern et al 2005). This article will discuss the choice of simvastatin and extended release niacin (niacin ER) combination therapy in the management of multiple dyslipidemia. 


\section{Pharmacology and pharmacokinetics of niacin ER and simvastatin}

\section{Simvastatin}

Simvastatin is butanoic acid, 2,2-dimethyl-,1,2,3,7,8,8ahexahydro-3-7-dimethyl-8-[2-(tetrahydro-4-hydroxy6-oxo-2H-pyran-2-yl)-ethyl]-1 naphthalenylester [1S[1 $\left.\left.\alpha, 3 \alpha, 7 \beta, 8 \beta\left(2 S^{*} 4 S^{*}\right),-8 \mathrm{a} \beta\right]\right]$ (Figure 1). Simvastatin is a white to off-white, non-hygroscopic, crystalline powder that is practically insoluble in water and freely soluble in chloroform, methanol, and ethanol. The empirical formula of simvastatin is $\mathrm{C}_{25} \mathrm{H}_{38} \mathrm{O}_{5}$ and its molecular weight is 418.57 (Kos Pharma 2008).

\section{Mechanism of action of simvastatin}

Simvastatin is a prodrug and is hydrolyzed to its active $\beta$-hydroxyacid form, simvastatin acid, after administration. Simvastatin is a specific inhibitor of 3-hydroxy-3methylglutaryl-coenzyme A (HMG-CoA) reductase, the enzyme that catalyzes the conversion of HMG-CoA to mevalonate, an early and rate-limiting step in the biosynthetic pathway for cholesterol. In addition, simvastatin reduces very low density lipoprotein (VLDL) and TG and increases HDL-cholesterol. The pleitropic effects of statins including simvastatin have been well studied (Robinson et al 2005).

\section{Niacin}

Niacin is nicotinic acid, or 3-pyridinecarboxylic acid. Niacin is a white, non-hygroscopic crystalline powder that is soluble in water, boiling ethanol, or propylene glycol. It is insoluble in ethyl ether. The empirical formula of niacin is $\mathrm{C}_{6} \mathrm{H}_{5} \mathrm{NO}_{2}$ and its molecular weight is 123.11 (Figure 2) (Kos Pharma 2008).

\section{Mechanism of action of niacin}

Niacin was found to inhibit lipolysis in adipocytes and reported as early as 1960 by Butcher et al (1968), who investigated its

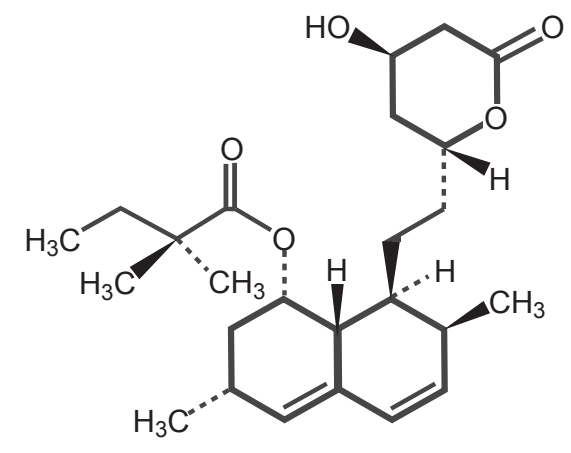

Figure I Structural formula of simvastatin.

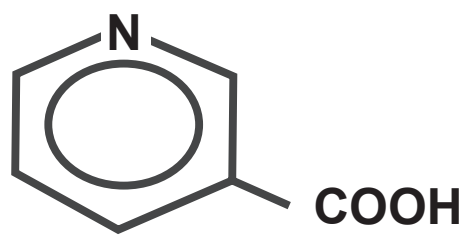

Figure 2 Structural formula of niacin.

effect on cyclic AMP. The investigators also found that niacin inhibits cyclic AMP production in epinephrine (adrenaline)exposed adipocytes. Later work suggested the presence of a G-protein-coupled cell surface receptor of the $\mathrm{G}_{\mathrm{ig}} / \mathrm{G}_{\mathrm{o}}$ type (Aktories et al 1983; Lorenzen et al 2001). In 2003, the niacin (nicotinic acid) receptor was identified as the human orphan receptor HM74 or the highly homologous, higher affinity HM74A, as well as the mouse homolog PUMA-G (protein upregulated in macrophages by interferon-[gamma]) (Tunaru et al 2003; Wise et al 2003; Soga et al 2003). HM74A (GPR109A) and PUMA-G are also identified as the pharmacologically active niacin receptors (Soudijn et al 2007). The receptors mediate inhibition of adenyl cyclase in adipocytes and thereby block lipolysis, accounting for the marked reduction of free fatty acids caused by niacin. Furthermore, there was an approximately $30 \%$ reduction in TG in fat-fed normal mice. In receptor-deficient mice, no reductions in plasma free fatty acid and triglyceride levels were seen (Tunaru et al 2003). Substantial mRNA expression of HM74A/PUMA-G was found in brown and white adipose tissue, spleen, adrenal, and lung, but expression was essentially absent in liver (Wise et al 2003).

Inhibition of lipolysis in adipocytes is a most important effect of niacin, but it is not yet proven that antilipolysis accounts for all or even most of the effects on plasma lipoproteins. Generally, plasma free fatty acid levels appear to increase production of VLDL, especially in states of elevated free fatty acids and VLDL overproduction (eg, obesity or diabetes). After an initial steep fall in plasma free fatty acids after ingestion of plain crystalline niacin, however, their levels rebound $2 \mathrm{~h}$ later, whereas hepatic production of VLDL remains suppressed for several additional hours (Wang et al 2001). An alternative mechanism, inhibition of hepatic diacylglycerol acyltransferase 2 in niacin, has also been proposed. In millimolar concentrations, niacin was shown to inhibit TG formation in HepG2 cells by diacylglycerol acyltransferase 2 inhibition and concomitantly to increase apolipoprotein B degradation (Jin et al 1991).

Niacin in millimolar concentrations also inhibited the uptake of HDL-apolipoprotein A-I by HepG2 cells (a model for liver) without affecting the uptake of cholesteryl 
ester from HDL (Jin et al 1997). This is a potential mechanism by which niacin raises HDL levels. Moreover, niacin is more effective in raising HDL than any other currently available drug (Guyton et al 2000). The increase in HDL-apolipoprotein A-I may augment reverse cholesterol transport, allowing removal of greater amounts of cholesterol from the vascular wall. Recently, niacin $(1 \mathrm{mM})$ was shown to activate the peroxisome proliferator-activated receptor-[gamma] in a monocytoid cell line, presumably via a metabolite of prostaglandin $\mathrm{D}_{2}$. Both cholesterol efflux and the transcription of efflux-related receptors, namely CD36 and ATP-binding cassette protein A1, were increased by niacin. The effect on CD36 was cyclo-oxygenase dependent, whereas the effect on ATP-binding cassette protein A1 was blocked by an inhibitor of protein kinase A (downstream from adenylyl cyclase) (Rubic et al 2004).

\section{Formulations of niacin and its metabolism}

Three types of niacin formulations are available: immediate release, sustained release and extended release. They differ in terms of their pharmacokinetic characteristics (McKenney et al 2003). Immediate release niacin (niacin IR) is absorbed quickly and produces peak serum concentrations within 30-60 min. It is metabolized predominantly via conjugation to nicotinuric acid, which is thought to be responsible for the flushing associated with niacin therapy. Niacin IR is generally given 3 times per day because of its rapid pharmacokinetics. Sustained release niacin (niacin SR) formulations are absorbed much more slowly, often taking 12-24 h (McKenney et al 2003). As a result, this preparation is metabolized to a greater extent via oxidation to nicotinamide and several pyrimidine breakdown products thought to be responsible for the hepatotoxicity associated with some SR formulations. Sustained release niacin is generally taken twice daily, but the absorption characteristics vary considerably across products. Extended release niacin (niacin ER) has a dissolution rate of 8-12 $\mathrm{h}$ and is absorbed at a rate intermediate to the other two types of niacin. As a result, niacin ER undergoes a more balanced metabolism via both pathways, which is believed to contribute to its improved safety profile. Niacin ER is administered once daily. Niacin ER is the only FDA approved form of niacin available within the United States for the treatment of dyslipidemia.

\section{Absorption and bioavailability of the combination of niacin ER and simvastatin}

The relative bioavailability of niacin (nicotinuric acid; $\mathrm{C}_{\max }$, and total urinary excretion as the surrogate), simvastatin, and simvastatin acid was evaluated in healthy volunteers $(n=42)$ after administration of two 1000/20 mg niacin/simvastatin combination tablets. Niacin exposure $\left(\mathrm{C}_{\max }\right.$ and $\left.\mathrm{AUC}\right)$ after Simcor $^{\circledR}$ (combination pill of simvastatin and niacin ER) was similar to that of a niacin ER formulation. However, simvastatin and simvastatin acid AUC after Simcor ${ }^{\circledR}$ increased by $23 \%$ percent and $41 \%$, respectively, compared with those of a simvastatin IR. The mean time to $\mathrm{C}_{\max }\left(\mathrm{T}_{\max }\right)$ for niacin ranged from 4.6 to $4.9 \mathrm{~h}$ and simvastatin from 1.9 to $2.0 \mathrm{~h}$. Afgter administration of 2 tablets of 1000/20 mg Simcor ${ }^{\circledR}$, the mean $\mathrm{C}_{\max }, \mathrm{T}_{\max }$, and $\mathrm{AUC}(0-\mathrm{t})$ for simvastatin acid, were $3.29 \mathrm{ng} / \mathrm{mL}, 6.56 \mathrm{~h}$, and $30.81 \mathrm{ng} \cdot \mathrm{h} / \mathrm{mL}$ respectively (Kos Pharma 2008).

\section{Clinical trials on niacin ER and simvastatin}

Numerous clinical trials have shown the efficacy and safety of simvastatin in the treatment of hyperlipidemia for secondary and primary prevention in dyslipidemic patients (Scandinavian Simvastatin Survival Study Group 1994). The efficacy and safety of combination of niacin ER and simvastatin have been studied recently (Goldberg et al 2000, Taylor et al 2004).

The HATS trial studied the progression of atherosclerosis at nine predefined proximal sites in the coronary circulation of 160 patients with coronary disease and low HDL-cholesterol ( $>35 \mathrm{mg} / \mathrm{dL}$ in men and $<40 \mathrm{mg} / \mathrm{dL}$ in women) (Brown et al 2001). Three years of treatment with a combination of simvastatin and immediate-release nicotinic acid increased HDL-cholesterol by $26 \%$ and decreased LDL-cholesterol by $42 \%$, relative to baseline. These improvements were accompanied by regression of atherosclerosis, measured as percentage luminal diameter of coronary arteries, compared with progression of atherosclerosis on placebo. In comparison to placebo, the 3-year primary event rate was reduced by 90 percent in patients receiving simvastatin/nicotinic acid therapy $(\mathrm{p}<0.03)$.

The Arterial Biology for the Investigation of the Treatment Effects of Reducing Cholesterol (ARBITER 2) (Taylor et al 2004) study confirmed that niacin ER shares these anti-atherogenic benefits. ARBITER 2 was a randomized, double-blind comparison of niacin ER (1000 mg once daily) and placebo when added to existing statin therapy in 167 men or women with HDL-cholesterol $<45 \mathrm{mg} / \mathrm{dL}$ and LDL-cholesterol $<130 \mathrm{mg} / \mathrm{dL}$. Treatment duration was 1 year. The primary endpoint was the change in carotid intima-media thickness (cIMT), assessed using ultrasound. This endpoint is highly predictive of coronary events, as 
shown by a 9-year follow-up of 146 men who underwent periodic carotid ultrasound and coronary angiography (Hodis et al 1998). The cIMT was significantly related to the risk of coronary events $(p<0.02)$, and an annual increase in this parameter of $0.03 \mathrm{~mm}$ was associated with a two-fold increase in the risk of myocardial infarction or coronary heart disease death, and a three-fold increase in the risk of any coronary event $(\mathrm{p}<0.001)$. The authors concluded that measurement of cIMT using ultrasound provided prognostic information beyond that available from coronary angiography and that cIMT provides a meaningful surrogate marker for coronary atherosclerosis.

The ARBITER 2 population was at high risk of coronary events. All patients had known coronary heart disease at baseline as a recruitment criterion, 28 percent had diabetes, 75\% were hypertensive, and 51\% had NCEP/ATPIII metabolic syndrome. Mean HDL-cholesterol at baseline was $39 \mathrm{mg} / \mathrm{dL}$ and mean LDL-cholesterol at baseline was $89 \mathrm{mg} / \mathrm{dL}$. Mean HDL-cholesterol did not change in the placebo group but was 20\% higher after treatment with niacin ER. Niacin ER also reduced TG compared with placebo. The lack of effect of study treatment on LDL-cholesterol was expected, as this parameter was already well controlled by pre-existing statin treatment before niacin was administered. Overall, the effects on the lipid profile of adding niacin to the regimen were consistent with the known therapeutic profile of this agent (Goldberg et al 2000; NCEP 2002).

During treatment with placebo, there was an increase in cIMT, whereas no significant change occurred during treatment with niacin ER, confirming the anti-atherogenic properties of this agent. Indeed, ARBITER 2 was the first clinical trial to demonstrate the superiority of lipid-modifying combination therapy (niacin ER with statin) over monotherapy (statin alone) by using cIMT as a clinically validated surrogate for coronary atherosclerosis. At the end of the ARBITER 2 study, 104 patients completed a further 12 months of openlabel treatment with niacin ER. The patients who were on placebo were switched to niacin and those on niacin continued therapy. The results of this study were termed as ARBITER 3. Initial results of ARBITER 3 show that the expected increase in HDL-cholesterol occurred in patients switching to niacin ER and that atherosclerosis regressed, with a mean reduction in cIMT of $0.04 \mathrm{~mm}$ from baseline $(\mathrm{p}=0.008)$ after $12-24$ months of treatment with niacin.

The SEACOAST trial (Ballantyne et al 2007) which was recently reported is a 24 -week double-blind, randomized, controlled trial in more than 640 patients with elevated non-HDL (type II hyperlipidemia or mixed dyslipidemia) compared simvastatin alone to a combination of niacin ER and simvastatin. This was a pharmaceutical industry sponsored trial. The study was designed to evaluate the safety and efficacy of Simcor ${ }^{\circledR}$ (combination pill of simvastatin and niacin ER) following simvastatin monotherapy. Patients enrolled in the trial were assigned to either a low-dose (20 mg) or high-dose (40 mg) simvastatin group. Patients in the low-dose group were randomized to receive niacin ER $2000 \mathrm{mg} / \mathrm{sim}$ astatin $20 \mathrm{mg}$, niacin ER $1000 \mathrm{mg} /$ simvastatin $20 \mathrm{mg}$, or simvastatin $20 \mathrm{mg}$. Patients in the high-dose group were randomized to receive niacin ER $2000 \mathrm{mg} /$ simvastatin $40 \mathrm{mg}$, niacin ER $1000 \mathrm{mg} / \mathrm{sim}$ astatin $40 \mathrm{mg}$ or simvastatin $80 \mathrm{mg}$. Those in the simvastatin control groups received a $50 \mathrm{mg}$ dose of niacin IR to maintain blinding.

Patients in the low-dose group receiving combination treatment achieved 14\% (1000 mg/20 mg) and 23\% $(2000 \mathrm{mg} / 20 \mathrm{mg})$ reductions in non-HDL compared with a $7 \%$ reduction with $20 \mathrm{mg}$ simvastatin therapy alone. Additionally, combination treatment significantly improved HDL by $18 \%$ (1000 mg/20 mg) and 25\% (2000 mg/20 mg) compared with $7 \%$ with $20 \mathrm{mg}$ simvastatin alone. Similarly, significant reductions in TG of $27 \%(1000 \mathrm{mg} / 20 \mathrm{mg})$ and $38 \%$ (2000 mg/20 mg) were seen in those treated with combination therapy compared with a $15 \%$ reduction with simvastatin monotherapy.

In the high-dose group, patients treated with combination therapy showed similar (non-inferior) improvements in nonHDL of $11 \%$ (1000 mg/40 mg) and 17\% (2000 mg/40 mg) compared with a $10 \%$ improvement with $80 \mathrm{mg}$ simvastatin therapy alone. Additionally, the high-dose combination group demonstrated significant improvements in HDL of $15 \%$ (1000 mg/40 mg) and 22\% (2000 mg/40 mg) compared with a $1 \%$ decrease among those receiving $80 \mathrm{mg}$ simvastatin monotherapy. Triglyceride levels among the high-dose combinations groups dropped $23 \%$ and $32 \%$, respectively, in contrast to a $0.3 \%$ increase in those randomized to $80 \mathrm{mg}$ simvastatin monotherapy. The study was not designed to measure any mortality or outcome data.

\section{Safety and tolerability of niacin ER and simvastatin combination}

The most common and important side effect of niacin is cutaneous flushing, with variable severity among patients. Other side effects include hepatic toxicity, hyperglycemia, gout, and rare cases of retinal macular edema. All of these effects are dose dependent and fully reversible given timely discontinuation. Gastrointestinal side effects, dizziness, pruritis, headache, and back pain are not uncommon. 
Much of the existing perception of niacin adverse effects is from studies of the IR and the very-slow release preparations (Knopp et al 1985). Hepatic toxicity and flushing have been favorably affected by recent preparations that attempt to strike a beneficial balance between the duration and the peak levels of plasma drug exposure. The recent publication of efficacy and safety data for the combination of a statin (including simvastatin) and niacin ER in the treatment of dyslipidemia (Ballantyne et al 2007; Karas et al 2008; Bays 2008 ) strongly suggests that the combination therapy would be more tolerable than reported in the recent past.

\section{Flushing}

Flushing occurs in almost all subjects who take lipidmodifying doses of niacin IR. It is the major reason for discontinuation of the drug, which has been described at rates as high as 25\%-40\% (Knopp et al 1985; Gibbons et al 1995; McKenney et al 1994). In the Coronary Drug Project (CDP Group 1975), the prescribed dose of niacin was $1000 \mathrm{mg} 3$ times daily, but mean adherence was only $66 \%$. Flushing appears to be decreased and tolerance improved with the use of niacin ER, because rates of discontinuation of this formulation due to flushing have not exceeded $6 \%$ in short-term trials (Knopp et al 1998; Goldberg et al 2000; Guyton et al 2000).

Flushing is caused by the release of prostaglandin $\mathrm{D}_{2}$ and possibly other eicosanoids from cells in the skin (Morrow et al 1992). Tachyphylaxis of flushing occurs usually with continued use of niacin. Regular, consistent dosing over days, weeks, and months reduces frequency and severity of flushing, accompanied by lesser increases of prostaglandin $\mathrm{D}_{2}$ after niacin ingestion (Stern et al 1991). Administering aspirin or other inhibitors of cyclooxygenase $30 \mathrm{~min}$ to $1 \mathrm{~h}$ before niacin intake can substantially reduce flushing (Oberwittler et al 2006). An aspirin dose of $325 \mathrm{mg}$ is commonly advised; an 81-mg dose may not be enough. Recently, an inhibitor of the prostaglandin $\mathrm{D}_{2}$ receptor 1 was found to inhibit niacin-induced flushing in mice and in early human trials; this compound is under clinical development (Cheng et al 2006).

The terms "no-flush niacin" and "flush-free niacin" are conventionally used for inositol hexanicotinate. In this compound, 6 molecules of nicotinic acid (niacin) are covalently attached to inositol by ester bonds. No published study has demonstrated that inositol hexanicotinate releases free niacin, demonstrably increases circulating niacin, or alters plasma lipid levels. Thus, there is no evidence that niacin in this formulation is bioavailable (Meyers et al 2006).
Laropiprant, a prostaglandin D2 receptor-1 antagonist, has shown considerable promise in reducing the associated flushing with niacin use and shown to improve compliance and dosing of niacin ER (Cheng et al 2006; Paolini et al 2008). This drug in combination with niacin ER is currently awaiting FDA approval.

\section{Hyperglycemia}

The potential for exacerbation of hyperglycemia in patients with diabetes represents another barrier to the successful therapeutic use of niacin to correct low HDL-cholesterol. Initial studies that suggested the substantial deterioration of glycemic control in patients with diabetes occurred in patients taking niacin IR. However, these studies used niacin doses as high as $4.5 \mathrm{~g} /$ day, which are rarely used in the statin era to treat hypercholesterolemia (Garg et al 1990). Clinical studies discussed below, including the CDP Study, noted only mild hyperglycemic effects as a result of niacin administration (CDP 1975; Canner et al 1986). Niacin ER at a dose of $2000 \mathrm{mg}$ /day was associated with a $5 \%$ increase in fasting plasma glucose (Guyton et al 1998). This hyperglycemia is caused by insulin resistance. Only a few studies have quantified insulin resistance in niacin-treated subjects. Some studies have suggested that the decrease in insulin sensitivity may average 20\%-28\% after 2 weeks of administration of niacin IR at $1000 \mathrm{mg}$ twice daily (Alvarsson et al 1996; Kelly et al 2000; Rasouli et al 2005; Chang et al 2006). In subjects aged older than 60 years, insulin sensitivity decreased by $55 \%-60 \%$ after niacin administration. Insulin secretory responsiveness does not decrease. In fact, insulin secretion may be increased as part of the homeostatic response to the decrease in the effectiveness of insulin action (Kahn et al 1989). The mechanism of peripheral insulin resistance may be related to a rebound increase in circulating fatty acids but not to increased muscle triglyceride content (Poynten et al 2003).

The discussion of niacin-induced insulin resistance is important for two clinical reasons. First, hyperglycemia itself appears to be associated with worsened cardiovascular outcomes (Adler et al 1999). However, it must be recalled that the overall impact of niacin is to reduce the residual cardiovascular risk associated with statin alone treatment of dyslipidemia. The second consequence of insulin resistance might be to increase the frequency of new onset of diabetes in patients at risk, such as those with the metabolic syndrome. Although this is a theoretical possibility, the 5-year CDP did not show significant differences between niacin treated and placebo-treated subjects in new prescriptions for insulin, new 
prescriptions for oral hypoglycemic drugs, or instances of dipstick-positive glycosuria (CDP Research Group 1975).

In the ADMIT study, 64 patients with diabetes and peripheral arterial disease, receiving an average niacin dose of $2.55 \mathrm{~g} /$ day, were compared with 61 similar patients receiving placebo over 48 weeks. The mean change in hemoglobin A1c (HbA1c) was $0.3 \%$ greater in the group receiving niacin $(\mathrm{p}<0.04)$, and insulin use was $13 \%$ more frequent in niacin users over the course of the trial, compared with $4 \%$ with placebo $(\mathrm{p}<0.09)$ (Elam et al 2000). Likewise, $\mathrm{HbA} 1 \mathrm{c}$ increased by $0.3 \%$ in 52 patients receiving niacin ER at $1500 \mathrm{mg} /$ day, compared with no change in 49 patients receiving placebo. In this study, niacin-treated patients tended to require additional hypoglycemic therapy more often than placebo-treated patients $(24 \%-29 \%$ of those taking niacin vs $16 \%$ with placebo, $\mathrm{p}<0.32$ ) (Grundy et al 2002). Thoenes et al (2007) reported that in 50 patients with the metabolic syndrome treated with niacin ER for 52 weeks, there was a significant improvement in endothelial function and a favorable effect on the lipid profile. Furthermore, there was no significant change in glucose intolerance in the study group.

Clinical trials with doses of niacin used clinically today appear to result in only minor deterioration of glycemic control in most patients with diabetes. The favorable effects of niacin on HDL-cholesterol, TG, lipoprotein (a), and LDL particle size, along with its lesser effect in lowering LDL-cholesterol, probably outweigh the small detriment in glycemic control in diabetes.

\section{Hepatotoxicity}

McKenney et al (1994) directly compared IR and SR niacin in a randomized clinical trial with dosage escalation from 500 to $3000 \mathrm{mg} /$ day over 30 weeks. None of the 23 patients taking niacin IR developed hepatotoxic effects, whereas 12 of 23 patients $(52 \%)$ taking niacin SR developed similar effects. The increase in liver toxicity with niacin SR mainly occurred with doses $>1500 \mathrm{mg} /$ day.

Niacin ER and simvastatin can cause abnormal liver tests. In a simvastatin-controlled, 24-week study with Simcor $^{\circledR}$ in 641 patients, there were no persistent increases (to more than $3 x$ the upper limit of normal) in serum transaminases (Ballantyne et al 2007). Persistent increases (to more than 3 times the upper limit of normal) in serum transaminases have occurred in approximately $1 \%$ of patients who received simvastatin in clinical studies (Scandinavian Simvastatin Survival Study Group 1994). When drug treatment was interrupted or discontinued in these patients, the transaminases levels usually fell slowly to pretreatment levels.
Liver function tests should be performed on all patients during therapy with combination therapy with simvastatin and niacin ER. It is recommended that liver function tests be performed before treatment begins, every 12 weeks for the first 6 months, and periodically thereafter, at approximately 6-month intervals (Kos Pharma 2008).

\section{Myopathy and other adverse events}

Niacin ER monotherapy has specifically amassed considerable clinical trial data that do not support an increased risk for muscle adverse experiences with niacin monotherapy. Similarly, the safety of niacin ER in combination with statins has likewise been assessed, and studies have demonstrated no sign of increased muscle toxicity over that of statins alone (HATS trial and SEACOAST trial). Many drugs that are potent inhibitors of CYP3A4 can increase the risk of myopathy by reducing the elimination of simvastatin. Hence when simvastatin is used with a potent inhibitor of CYP3A4, elevated plasma levels of HMGCoA reductase inhibitory activity can increase the risk of myopathy and rhabdomyolysis, particularly with higher doses of simvastatin. In patients with renal failure and elderly, caution should be exercised in using high doses of statins with niacin ER and may need frequent monitoring of muscle and liver enzymes.

\section{Patient perspectives}

It is important to counsel patients about the role of niacin in improving their lipid profile and reducing their cardiovascular risk. Physicians should review the expected side effects with their patients before starting therapy and reinforce the importance of staying on therapy. Although most patients can expect to experience some flushing even with niacin ER formulations, tolerance to the flushing generally develops with continued use. In addition, several measures can reduce the frequency and severity of flushing. First, niacin therapy needs to be initiated at a low dose and then slowly titrated upward to achieve the treatment goal. Second, patients may take aspirin $325 \mathrm{mg}$ or another non-steroidal anti-inflammatory drug 30 min before the niacin dose to reduce prostaglandin-mediated flushing (Oberwittler et al 2006). Third, physicians should advise patients to avoid spicy foods, hot beverages, and hot showers shortly after taking niacin. Patient should avoid any interruptions in niacin therapy to continue any tolerance to flushing that has developed. If niacin is interrupted for more than 1 week, treatment needs to be restarted at the lowest dose and again titrated upward. The niacin ER formulation is given at bedtime, which may further reduce the awareness of flushing. The simplified regimen may also improve patient 
adherence. Practitioners should discuss these steps with their patients and should provide instructions in a written form (see Table 1).

\section{Conclusion}

The combination of niacin ER with a statin addresses two key sources of cardiovascular risk: low HDL-cholesterol and elevated LDL-cholesterol. The availability of Niaspan ${ }^{\circledR}$, a prolonged-release formulation of nicotinic acid with improved tolerability compared with the immediate-release version facilitates the delivery of this therapy. The recently published SEACOAST trial (Ballantyne et al 2007) demonstrated the safety and efficacy of combination simvastatin and niacin ER in small group of patient population for period of 6 months. The randomized, double-blind ARBITER 2 study (Taylor et al 2004) demonstrated the benefits of Niaspan ${ }^{\circledR}$ plus a statin in terms of inhibition of atherosclerosis. Although ARBITER 2 was not powered to detect significant differences in event rates, there was a trend towards a reduction in cardiovascular events in the Niaspan group, compared with placebo.

The Atherothrombosis Intervention in Metabolic Syndrome with Low HDL-C/High Triglyceride and Impact on Global Health Outcomes (AIM-HIGH) study will explore quantitatively the potential of aggressive intervention with Niaspan ${ }^{\circledR}$ and a statin to improve cardiovascular event rates. This trial, jointly sponsored by the US National Heart, Lung, and Blood Institute and Kos Pharmaceuticals Inc (now Abbott Pharmaceuticals), is currently recruiting a population of 3300 patients with established coronary heart disease, atherogenic dyslipidemia (low HDL-cholesterol and high TG), and LDL-cholesterol controlled to current US guideline goals (NCEP criteria) at 60 sites in the US and Canada. Patients will be randomized to receive double-blind treatment with Niaspan ${ }^{\circledR}$ plus a statin or to statin monotherapy for

Table I Recommended dosing regimen of niacin ER

\begin{tabular}{ll}
\hline Week(s) & Daily dose of niacin ER \\
\hline I to 4 & $500 \mathrm{mg}$ \\
5 to 8 & $1000 \mathrm{mg}$ \\
At least 4 weeks & $1500 \mathrm{mg}$ \\
At least 4 weeks & $2000 \mathrm{mg}$
\end{tabular}

Notes: The dose of niacin extended-release should not be increased by more than $500 \mathrm{mg}$ daily every 4 weeks.

The efficacy and safety of doses of simvastatin and niacin ER combination greater than 2000/40 $\mathrm{mg}$ daily have not been studied and are therefore not recommended. Combination of simvastatin and niacin EF (Simcor ${ }^{\circledR}$ tablets) should be taken whole and should not be broken, crushed, or chewed before swallowing.
6 years. The primary outcome measure will be a composite of cardiovascular death, non-fatal myocardial infarction, non-hemorrhagic stroke, or hospitalization for acute coronary syndrome with objective evidence of ischemia. AIM-HIGH will define the potential of aggressive management of both low HDL-cholesterol and hyperlipidemia to reduce cardiovascular event rates.

The Heart Protection Study 2: Treatment of HDL to Reduce the Incidence of Vascular Events (HPS2-THRIVE) is an ongoing trial combining simvastatin and extended-release niacin plus a D prostanoid 1 receptor antagonist laropiprant, to inhibit the prostaglandin D2-mediated flushing side effect in comparison with simvastatin monotherapy in 20,000 patients with coronary heart disease.

In our opinion, the AIM HIGH and HPS2-THRIVE studies will give us answers to the question whether the combination of simvastatin with niacin ER will reduce residual cardiovascular risk in comparison to statin therapy alone. At this point of time, the combination of simvastatin with niacin ER is an effective treatment of the specific components of dyslipidemia, namely improving the profiles of elevated TG and LDL-cholesterol and low levels of HDL-cholesterol.

\section{Disclosures}

None of the authors has any conflicts of interest to disclose.

\section{References}

Adler AI, Neil HA, Manley SE, et al. 1999. Hyperglycemia and hyperinsulinemia at diagnosis of diabetes and their association with subsequent cardiovascular disease in the United Kingdom Prospective Diabetes Study (UKPDS 47). Am Heart J, 138:S353-S9.

Aim High: Niacin plus statin to prevent vascular events. Clinical trials. gov-NCT 00120289.

Aktories K, Schultz G, Jakobs KH. 1983. Islet-activating protein prevents nicotinic acid-induced GTPase stimulation and GTP but not GTP gamma S-induced adenylate cyclase inhibition in rat adipocytes. FEBS Lett, 156:88-92.

Alvarsson M, Grill V. 1996. Impact of nicotinic acid treatment on insulin secretion and insulin sensitivity in low and high insulin responders. Scand J Clin Lab Invest, 56:563-70.

Ballantyne CM, Davidson M, McKenney J, et al. 2007. Safety and efficacy of a combination of extended-release niacin and simvastatin in patients with dyslipedemia (SEACOAST) - a dose ranging study [abstract]. AHA Scientific Conference, Chicago.

Bays H. 2008. Safety of niacin and simvastatin combination therapy. Am J Cardiol, 101:3-8.

Butcher RW, Baird CE, Sutherland EW. 1968. Effects of lipolytic and antilipolytic substances on adenosine 3', 5'-monophosphate levels in isolated fat cells. $J$ Biol Chem, 243:1705-12.

Brown BG, Zhao XQ, Chait A, et al. 2001. Simvastatin and niacin, antioxidant vitamins, or the combination for the prevention of coronary disease. N Engl J Med, 345:1583-92.

Canner PL, Berge KG, Wenger NK, et al. 1986. Fifteen-year mortality in Coronary Drug Project patients: long-term benefit with niacin. $J \mathrm{Am}$ Coll Cardiol, 8:1245-55. 
Chang AM, Smith MJ, Galecki AT, et al. 2006. Impaired beta-cell function in human aging: response to nicotinic acid-induced insulin resistance. J Clin Endocrinol Metab, 91:3303-9.

Cheng K, Wu TJ, Wu KK, et al. 2006. Antagonism of the prostaglandin D2 receptor 1 suppresses nicotinic acid-induced vasodilation in mice and humans. Proc Natl Acad Sci U S A, 103:6682-7.

Coronary Drug Project Research Group. Clofibrate and niacin in coronary heart disease. JAMA, 1975.231:360-381.

Elam MB, Hunninghake DB, Davis KB, et al. 2000. Effect of niacin on lipid and lipoprotein levels and glycemic control in patients with diabetes and peripheral arterial disease: the ADMIT [Arterial Disease Multiple Intervention Trial] study. A randomized trial. JAMA, 284:1263-70.

Ganji SH, Kamanna VS, Kashyap ML. 2003. Niacin and cholesterol: role in cardiovascular disease. J Nutr Biochem, 14:298-305.

Garg A, Grundy SM. 1990. Nicotinic acid as therapy for dyslipidemia in non-insulin-dependent diabetes mellitus. JAMA, 264:723-6.

Gibbons LW, Gonzalez V, Gordon N, et al. 1995. The prevalence of side effects with regular and sustained-release nicotinic acid. Am J Med, 99:378-85.

Ginsberg HN. 2000. Insulin resistance and cardiovascular disease. J Clin Invest, 106:453-8.

Goldberg A, Alagona P Jr, Capuzzi DM, et al. 2000. Multiple-dose efficacy and safety of an extended-release form of niacin in the management of hyperlipidemia. Am J Cardiol, 85:1100-5.

Grundy et al. 2004. Implications of the recent clinical trials for the National Education Program Adult Treatment Panel Guidelines - Circulation: Introduction.

Grundy SM, Vega GL, McGovern ME, et al. for the Diabetes Multicenter Research Group. 2002. Efficacy, safety, and tolerability of once-daily niacin for the treatment of dyslipidemia associated with type 2 diabetes: results of the assessment of diabetes control and evaluation of the efficacy of Niaspan trial. Arch Intern Med, 162:1568-76.

Guyton JR, Blazing MA, Hagar J, et al. 2000. Extended-release niacin vs gemfibrozil for the treatment of low levels of high-density lipoprotein cholesterol. Arch Intern Med, 160:1177-84.

Guyton JR, Blazing MA, Hagar J, et al. 2000. Extended-release niacin versus gemfibrozil for treatment of low levels of high density lipoprotein cholesterol. Arch Intern Med, 160:1177-84.

Guyton JR, Goldberg AC, Kreisberg RA, et al. 1998. Effectiveness of oncenightly dosing of extended release niacin alone and in combination for hypercholesterolemia. Am J Cardiol, 82:737-43.

Hodis HN, Mack WJ, LaBree L, et al. 1998. The role of carotid arterial intima-media thickness in predicting clinical coronary events. Ann Intern Med, 128:262-9.

Health Protection Study-2-(HPS2-THRIVE). clinicaltrials.gov00461360 .

Jin FY, Kamanna VS, Kashyap ML. 1999. Niacin accelerates intracellular ApoB degradation by inhibiting triacylglycerol synthesis in human hepatoblastoma (HepG2) cells. Arterioscler Thromb Vasc Biol, 19:1051-9.

Jin FY, Kamanna VS, Kashyap ML. 1997. Niacin decreases removal of high-density lipoprotein apolipoprotein A-I but not cholesterol ester by Hep G2 cells. Implication for reverse cholesterol transport. Arterioscler Thromb Vasc Biol, 17:2020-8.

Kahn SE, Beard JC, Schwartz MW, et al. 1989. Increased beta-cell secretory capacity as mechanism for islet adaptation to nicotinic acid-induced insulin resistance. Diabetes, 38:562-8.

Kastelein JJP. 2005. The realities of dyslipidaemia: what do the studies tell us? Eur Heart J, 7(Suppl F):F27-F33.

Karas RH, AlSheikh-Ali AA. 2008: The safety of niacin in the US Food and Drug Administration Adverse Event Reporting Database. Am J Cardiol, 101:10-3.

Kelly JJ, Lawson JA, Campbell LV, et al. 2000. Effects of nicotinic acid on insulin sensitivity and blood pressure in healthy subjects. J Hum Hypertens, 14:567-72.
Knopp RH, Ginsberg J, Albers JJ, et al. 1985. Contrasting effects of unmodified andtime-release forms of niacin on lipoproteins in hyperlipidemic subjects: clues to mechanism of action of niacin. Metabolism, 34:642-50.

Knopp RH, Alagona P, Davidson M, et al. 1998. Equivalent efficacy of a time-release form of niacin (Niaspan) given once a-night versus plain niacin in the management of hyperlipidemia. Metabolism, 47:1097-104.

Kos Pharmaceuticals (currently) Abbott Pharmaceuticals DN1628V4simcor-021408 Prescribing Information 2008.

Krauss RM. 2004. Lipids and lipoproteins in patients with type 2 diabetes. Diabetes Care 27:1496-504.

Lorenzen A, Stannek C, Lang H, et al. Characterization of a G protein-coupled receptor for nicotinic acid. Mol Pharmacol 2001. 59:349-57.

McGovern ME. 2005. Niaspan ${ }^{\circledR}$ : creating a new concept for raising HDL-cholesterol. Eur Heart J, 7(Suppl F):F41-F7.

McKenney JM, Proctor JD, Harris S, et al. 1994. A comparison of the efficacy and toxic effects of sustained- vs. immediate-release niacin in hypercholesterolemic patients. JAMA, 271:672-7.

Meyers CD, Carr MC, Park S, et al. 2003. Varying cost and free nicotinic acid content in over-the-counter niacin preparations for dyslipidemia. Ann Intern Med, 139:996-1002.

Morgan JM, Capuzzi DM, Guyton JR, et al. 1996. Treatment effect of Niaspan, a controlled-release niacin, in patients with hypercholesterolemia: a placebo-controlled trial. J Cardiovasc Pharmacol Ther, 1:195-202.

Morrow JD, Awad JA, Oates JA, et al. 1992. Identification of skinas a major site of prostaglandin $\mathrm{D} 2$ release following oral administration of niacin in humans. J Invest Dermatol, 98:812- 15.

National Cholesterol Education Program (NCEP). 2002. Expert panel on detection (third report), evaluation, and treatment of high blood cholesterol in adults (Adult Treatment Panel III) final report. Circulation, 106:3143-421.

Oberwittler H, Baccara-Dinet M. Clinical evidence for use of acetyl salicylic acid in control of flushing related to nicotinic acid treatment. Int J Clin Pract 2006. 60:707-15.

Paolini JF, Mitchell YB, Reyes R, et al. 2008. Effects of laropiprant on nicotinic acid-induced flushing in patients with dyslipedemia. Am J Cardiol, 101:625-8

Poynten AM, Gan SK, Kriketos AD, et al. 2003. Nicotinic acid-induced insulin resistance is related to increased circulating fatty acids and fat oxidation but not muscle lipid content. Metabolism, 52:699-704.

Rasouli N, Hale T, Kahn SE, et al. 2005. Effects of short-term experimental insulin resistance and family history of diabeteson pancreatic beta-cell function in nondiabetic individuals. J Clin Endocrinol Metab, 90:5825-33

Robinson JG, Smith B, Maheshwari N, et al. 2005. Pleiotrophic effects of statins - benefits beyond LDL reduction? J Am Coll Cardiol, 46:1855-62.

Rubic T, Trottmann M, Lorenz RL. 2004. Stimulation of CD36 and the key effector of reverse cholesterol transport ATP-binding cassette A1 in monocytoid cells by niacin. Biochem Pharmacol, 67:411-9.

Scandinavian Simvastatin Survival Study Group. 1994. Randomized trial of cholesterol lowering in 4444 patients with coronary heart disease : Scandinavian Simvastatin Survival Study (4S). Lancet, 344:1383-9.

Soga T, Kamohara M, Takasaki J, et al. 2003. Molecular identification of nicotinic acid receptor. Biochem Biophys Res Commun, 303:364-9.

Soudijn W, van Wijngaarden I, Ijzerman AP. 2007. Nicotinic acid receptor subtypes and their ligands. Med Res Rev, 27:417-33.

Stern RH, Spence JD, Freeman DJ, et al. 1991. Tolerance to nicotinic acid flushing. Clin Pharmacol Ther, 50:66-70.

Taylor AJ, Sullenberger LE, Lee HJ, et al. 2004. Arterial Biology for the Treatment Effects of Reducing Cholesterol 2 (ARBITER 2 Study). Circulation, 110:3512-7. 
Thoenes M, Oguchi A, Nagamia S, et al. 2007. The effects of extendedrelease niacin on carotid intimal medial thickness, endothelial function, and inflammatory markers in patients with the metabolic syndrome Int J Clin Pract, 61:1942-8.

Tunaru S, Kero J, Schaub A, et al. 2003. PUMA-G and HM74 are receptors for nicotinic acid and mediate its antilipolytic effect. Nat Med, $9: 352-5$.
Wang W, Basinger A, Neese RA, et al. 2001. Effect of nicotinic acid administration on hepatic very low density lipoprotein-triglyceride production. Am J Physiol Endocrinol Metab, 280:E540-E7.

Wise A, Foord SM, Fraser NJ, et al. 2003. Molecular identification of high and low affinity receptors for nicotinic acid. J Biol Chem, 278:9869-74. 
